\title{
The effects of global climate change on the cycling and processes of persistent organic pollutants (POPs) in the North Sea
}

\author{
K. O'Driscoll ${ }^{1}$, B. Mayer ${ }^{2}$, J. Su ${ }^{2}$, and M. Mathis ${ }^{2}$ \\ ${ }^{1}$ Marine Research Group, School of Planning, Architecture \& Civil Engineering, Queen's University Belfast, UK \\ ${ }^{2}$ Institute of Oceanography, University of Hamburg, Bundesstrasse 53, Hamburg 20146, Germany \\ Correspondence to: K. O’Driscoll (kieran.odriscoll@qub.ac.uk)
}

Received: 14 August 2013 - Published in Ocean Sci. Discuss.: 10 September 2013

Revised: 1 April 2014 - Accepted: 3 April 2014 - Published: 27 May 2014

\begin{abstract}
The fate and cycling of two selected legacy persistent organic pollutants (POPs), PCB 153 and $\gamma-\mathrm{HCH}$, in the North Sea in the 21 st century have been modelled with combined hydrodynamic and fate and transport ocean models (HAMSOM and FANTOM, respectively). To investigate the impact of climate variability on POPs in the North Sea in the 21st century, future scenario model runs for three 10year periods to the year 2100 using plausible levels of both in situ concentrations and atmospheric, river and open boundary inputs are performed. This slice mode under a moderate scenario (A1B) is sufficient to provide a basis for further analysis. For the HAMSOM and atmospheric forcing, results of the IPCC A1B (SRES) 21st century scenario are utilized, where surface forcing is provided by the REMO downscaling of the ECHAM5 global atmospheric model, and open boundary conditions are provided by the MPIOM global ocean model.

Dry gas deposition and volatilization of $\gamma-\mathrm{HCH}$ increase in the future relative to the present by up to $20 \%$ (in the spring and summer months for deposition and in summer for volatilization). In the water column, total mass of $\gamma-\mathrm{HCH}$ and PCB 153 remain fairly steady in all three runs. In sediment, $\gamma$-HCH increases in the future runs, relative to the present, while PCB 153 in sediment decreases exponentially in all three runs, but even faster in the future, due to the increased number of storms, increased duration of gale wind conditions and increased water and air temperatures, all of which are the result of climate change. Annual net sinks exceed sources at the ends of all periods.

Overall, the model results indicate that the climate change scenarios considered here generally have a negligible influence on the simulated fate and transport of the two POPs in
\end{abstract}

the North Sea, although the increased number and magnitude of storms in the 21st century will result in POP resuspension and ensuing revolatilization events. Trends in emissions from primary and secondary sources will remain the key driver of levels of these contaminants over time.

\section{Introduction}

Persistent organic pollutants (POPs) are highly toxic chemicals. As their name suggests, they degrade slowly and, thus, have long half lives, generally on the order of years to tens of years. In productive ocean waters, which are often shallow and coastal, POPs enter the food web, bioaccumulate in different kinds of tissues and become hazardous to living organisms including humans (AMAP, 1998). Even though primary emissions of legacy POPs have been declining, concentrations of some POPs in the atmosphere over open ocean areas have not reduced accordingly which can be the result of emissions from capacitors such as oceans, soil and sediments, e.g. Nizzetto et al. (2010), Gioia et al. (2008). Hence, the study of POPs under a changing climate scenario is important and interesting.

POPs in the ocean are subject to a wide range of processes including mechanical, chemical, physical and biological processes. For the North Sea, large amounts of POPs enter the system from the surrounding countries. Major entrance pathways of POPs to the North Sea are through atmospheric deposition, river inputs and adjacent seas, i.e. the North Atlantic Ocean, the English Channel and the Baltic Sea (see Fig. 1). Ilyina et al. (2006), who developed the fate and transport ocean model (FANTOM), were the first to investigate 
the fate of POPs in the southern North Sea with a highresolution combined hydrodynamic and fate and transport model. O'Driscoll et al. (2013) extended the model domain to the entire North Sea system while improving several POPs processes in the model and the quality of input and forcing data.

In this study, we have selected two very different legacy POPs for the simulations. Lindane, $\gamma-\mathrm{HCH}$, is a legacy POP that was widely used as an insecticide but was banned under the Stockholm Convention. Although one of the lesser hydrophobic POPs, it mostly dissolves in water and has halflives of about 1.2 and 1.6 years in water and sediment, respectively (Ngabe et al., 1993; Hornsby et al., 1996). PCB 153 , on the other hand, is very hydrophobic, so it does not readily dissolve in water but mostly sorbs to organic material in aquatic environments. It is also subject to the terms of the Stockholm Convention. It causes a host of medical problems in humans, see e.g. Ghosh et al. (2011) and references therein. It has half-lives of about 13.7 and 18.8 years in water and sediment, respectively (Sinkkonen and Paasivirta, 2000). For a further discussion of properties influencing the fate and transport of $\gamma-\mathrm{HCH}$ and PCB 153 in the marine environment, see O'Driscoll et al. (2013). A complete list of physical-chemical property values used with the simulations is provided in the Supplement (Table S1).

A number of recent modelling studies have investigated the effects of global climate change on POPs. Lamon et al. (2009) used a multimedia chemical fate model to evaluate the influence of climate change on the global distribution of PCB 28 and PCB 153. They found that higher temperatures increased primary and secondary volatilization emissions of PCBs, thereby enhancing transport from temperate regions to the Arctic, while the largest relative increase in concentrations of both PCB congeners in air occurs in the high Arctic and the remote Pacific Ocean. Their modelling results indicate that climate change will increase volatilization emissions and increase mobility of POPs with properties similar to those of PCBs. Reviewing the roles of multimedia environmental fate and food-web bioaccumulation models to investigate potential POP changes due to climate change, Gouin et al. (2013) found that alterations to exposure concentrations are typically within a factor of 2 of the baseline output, while recommending caution when interpreting the relative importance of global climate change on how these changes influence chemical fate and bioavailability. In their overview, Armitage et al. (2011) provide context for northern residents of the relative importance of different aspects of exposure to organic contaminants related to global climate change. Important processes include the influence of temperature on contaminant amplification and distribution, particularly in the Arctic where accumulation is expected to be sensitive to changing ice cover and precipitation events. Using a global-scale multimedia chemical fate model, Wöhrnschimmel et al. (2013) analyse and quantify the impact of climate change on emissions and fate of two legacy POPs, PCB153, and $\alpha-\mathrm{HCH}$, and their transport to the Arctic. Given a phase of ongoing primary emissions, they found that modelled concentrations in Arctic contamination increase by up to a factor of 2 in air and water, and are driven mostly by changes in emission patterns. Following a phase-out, they found increases of up to a factor of 2 in air and 4 in water, which are mostly attributable to changes in transport and fate of chemicals. These changes are also relative to the 20th century climate baseline model output since their model runs were for the period 1900-2100.

However, there have to date been no studies investigating the fate of POPs in coastal or shelf seas with high-resolution simulations under climate change scenarios. Therefore, we feel that the present study is an important contribution to the literature, by complementing previous studies and giving us insight into the effect of climate change on important POP processes in shelf seas, thus helping policy makers to make well-informed decisions.

To investigate the impact of climate variability on POPs in the North Sea in the 21st century, future scenario model runs for three 10-year periods to the year 2100 (2006-2015, 2046-2055 and 2090-2099) using plausible levels of both in situ concentrations and atmospheric, river and open boundary inputs are performed.

A 3-D hydrodynamic model is a necessary prerequisite tool for modelling their fate in the ocean. For this purpose, we have applied a very high resolution version of the Hamburg Shelf Ocean Model (HAMSOM) for the North Sea developed at the Institute of Oceanography, University of Hamburg, see O’Driscoll et al. (2013) for details.

\section{Model description and approach}

\subsection{Model description}

Here, we present a brief overview of both the HAMSOM and FANTOM models; for a more detailed description see O'Driscoll et al. (2013). Comprehensive descriptions of both models are available in the literature for the FANTOM (Ilyina et al., 2006) and HAMSOM (Backhaus, 1985; Pohlmann, 2006).

Model bathymetry is obtained from Larsen and She (2001) and presented in Fig. 1. Time steps $(5 \mathrm{~min})$ are the same in both models.

The HAMSOM is a baroclinic shallow water equation ocean circulation model, which has been successfully applied to different regional seas, see e.g. Mayer et al. (2010), Su and Pohlmann (2009), and O'Driscoll et al. (2013). Meteorological forcing is provided by the REMO downscaling of the ECHAM5 global atmospheric model IPCC A1B (SRES) 21 st century scenario, see Jacob et al. (2001) and Roeckner et al. (2006). Open boundary conditions (temperature, salinity and sea surface height) are provided by the global ocean model MPIOM, see Jungclaus et al. (2006). Temperature and 


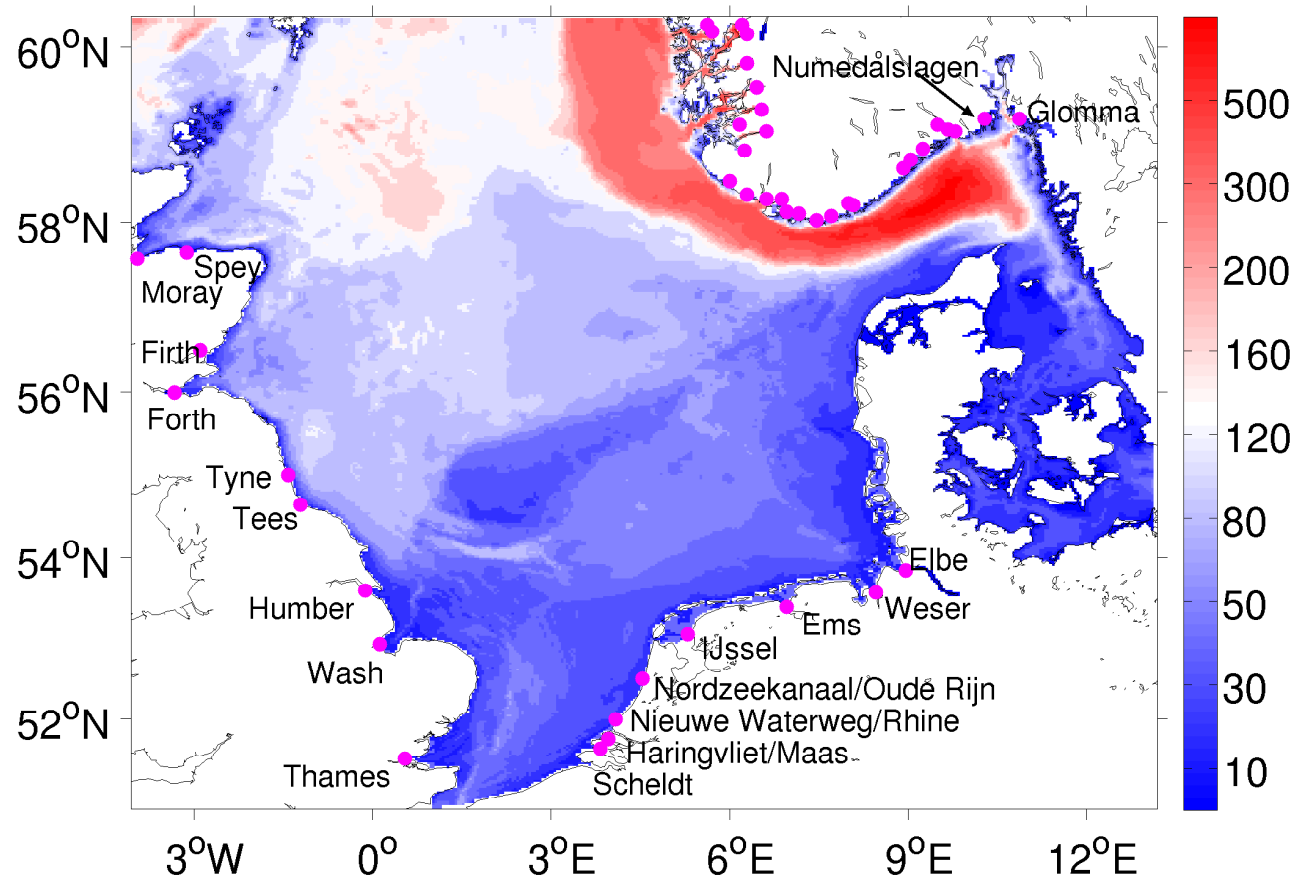

Figure 1. The model domain with topography (metres). River sources of freshwater are shown by magenta dots.

salinity are prescribed under inflow conditions, while a radiation condition by Orlanski (1976) is utilized when the flow is outward. Locations of freshwater runoff into the model domain are shown in Fig. 1. Monthly climatological river runoff data are used for the entire run, see O'Driscoll et al. (2013).

The FANTOM is a 3-D Eulerian model for simulating the fate of POPs and other pollutants in coastal regions and shelf seas. Model processes fall into five main categories: transport due to advection and diffusion; air-sea exchange; phase (re-)distribution; degradation; exchange between the water column and sediment (deposition and resuspension). A summary of model processes is provided in the Supplement (Sect. S2). See O'Driscoll et al. (2013) and Ilyina et al. (2006) for full details. For reasonable simulation of POPs exchange between water column and sediment, the FANTOM has 20 sediment layers representing the upper $2 \mathrm{~cm}$ of the sediment bed.

Both models (HAMSOM and FANTOM) have been evaluated for the period 1996-2005 (O'Driscoll et al., 2013) and the simulations were shown to be of a very satisfactory quality relative to observations.

\subsection{Model approach}

Since estimates of future concentration levels of POPs in the atmosphere, oceans and rivers are not available, our approach was to reutilize 2005 values in the atmosphere, rivers and at the open ocean boundaries for every year of the simulations - that is seasonally varying concentrations are reused each year - while using the (final) result for POP concentrations in water and sediment from the 1996-2005 runs of O'Driscoll et al. (2013) as the initial condition for all three future runs. In this way, we attribute differences between the three 10-year simulations to climate change only. Atmospheric concentrations of POPs are provided by output from the atmospheric model of the MSC-E, EMEP (Gusev et al., 2009) for the year 2005, while concentrations for riverine input have been calculated from available data sets for the year 2005. We think this is a reasonable approach since concentrations in the atmosphere, rivers and oceans (primary sources) were greatly reduced in 2005 relative to 1996 (O'Driscoll et al., 2013) but capacitors (secondary sources) will continue to play an important role in the coming years due to their long-term storage ability, see discussions in Nizzetto et al. (2010) and Lohmann et al. (2007). Concerning external pollutant conditions, since, to date, we have only vague ideas about future input changes of POPs through the atmosphere or rivers (net North Atlantic input into the North Sea is negligible), we cannot perform a projection for the POPs as we do for the climate itself. When considering changes in both climate and POP inputs, we would not be able to distinguish which of these is responsible for changes in POPs. We can make some estimates on the likely direction and magnitude of change based on emission, fate and transport rates. For example, using a global mass balance model approach, Breivik et al. (2007) found that emissions of PCBs $\left(\Sigma \mathrm{PCB}_{22}\right)$ will decrease exponentially in the 21 st century, while Wöhrnschimmel et al. (2013), using a global model, found that PCB 153 and $\alpha-\mathrm{HCH}$ concentrations in the Arctic will decrease by $2-3$ orders of magnitude in 2100 relative to 2005 mostly due to 

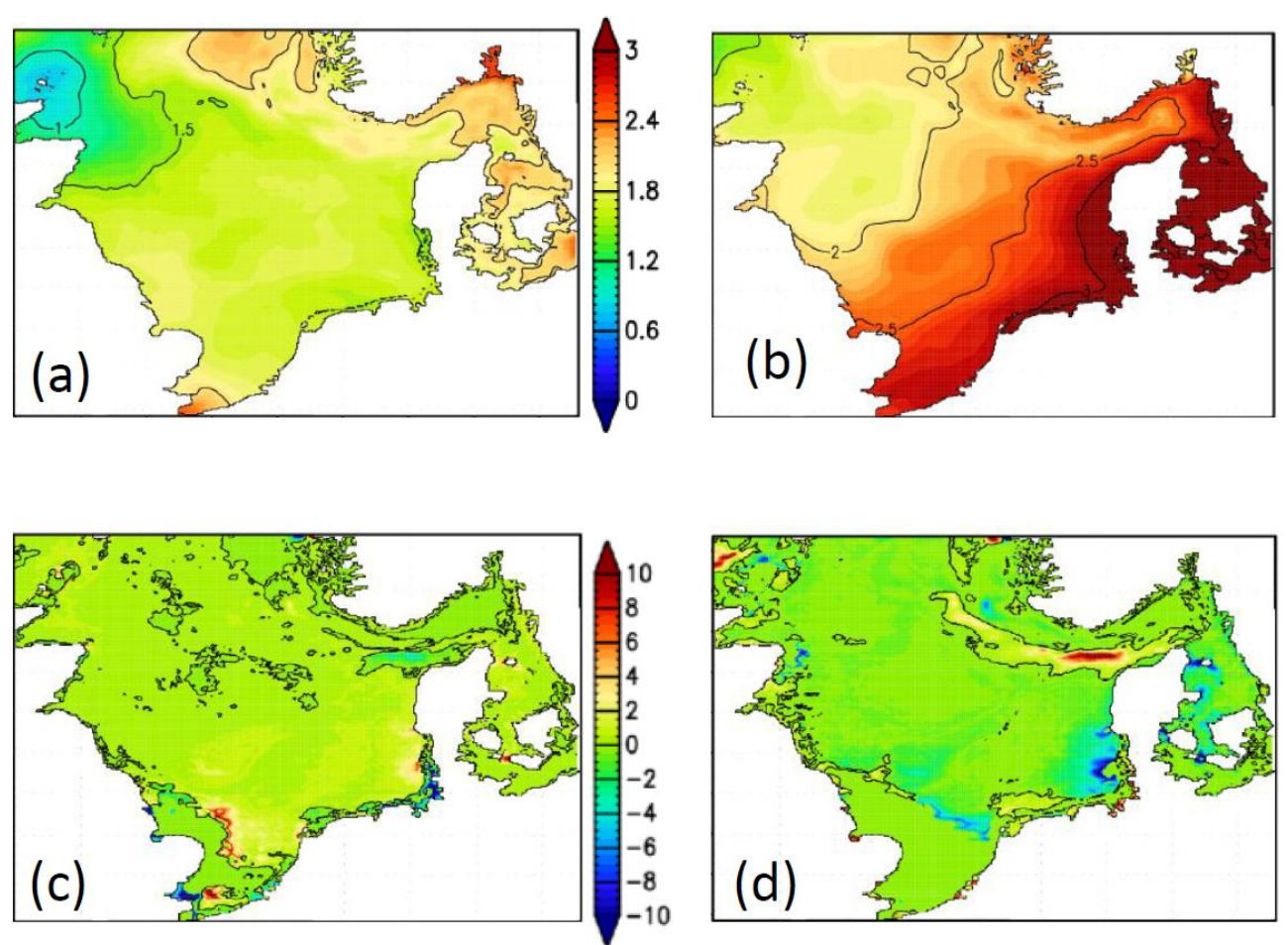

Figure 2. Distributions of 21st century trends. (a) SST in summer (June, July, August); (b) SST in winter (December, January, February), both in ${ }^{\circ} \mathrm{C}$ per 100 years; (c) relative occurrence of erosion in percentage points per 100 years; (d) relative occurrence of deposition in percentage points per 100 years. The upper scale is for (a) and (b), the lower scale for (c) and (d).

phase-out. So we can expect to find similar decreases in atmospheric and open ocean concentrations at lower latitudes. However, since the area of interest in this work is the regional, semi-enclosed, shallow North Sea, we again stress that concentrations of some POPs in the atmosphere over open ocean areas have not reduced accordingly, which can be the result of emissions from capacitors such as oceans, soil and sediments (Nizzetto et al., 2010; Gioia et al., 2008) and so we can expect capacitors to be important in the coming years due to their long-term storage ability (Nizzetto et al., 2010; Lohmann et al., 2007).

We chose the A1B scenario because it is a moderate choice. A more extreme scenario would introduce more variance into the solution, resulting in more biased conclusions. Also, since more computer power is required to simulate other scenarios, which will not lead to any new conclusion in addition to those of the present study, it is not worth the effort involved.

Monthly climatological river runoff data for major continental and British rivers are used for the entire period in both models (O’Driscoll et al., 2013).

\section{Results and discussion}

\subsection{Hydrodynamics}

The basic hydrodynamic results for the model domain are as follows. Analysis of the atmospheric forcing data for the North Sea reveals a continuous increase of the spatially averaged $2 \mathrm{~m}$ air temperature of $2.38^{\circ} \mathrm{C}$ within the scenario period 2001-2100, where warming in winter is $25 \%$ higher than the mean, but is $22 \%$ lower in summer. Similarly, the volume-averaged water temperature of the North Sea increases by $2.0^{\circ} \mathrm{C}$ (to 2100 ) with warming $4 \%$ weaker in summer and $4 \%$ stronger in winter in 2100 relative to 2000 , whereas sea-surface temperature (SST) trends show average increases of 1.66 and $2.31^{\circ} \mathrm{C}$ in summer and winter, respectively (see Fig. $2 \mathrm{a}$ and b). The analysis of $10 \mathrm{~m}$ wind speed does not show a significant change of the mean wind speeds throughout the year (in 2100). Local maximum wind speeds, however, indeed show an increase of $1.38 \mathrm{~m} \mathrm{~s}^{-1}$ in winter and a decrease of $0.75 \mathrm{~m} \mathrm{~s}^{-1}$ in summer. The duration of gale wind conditions per year, indicated by mean wind speeds greater than $17 \mathrm{~m} \mathrm{~s}^{-1}$, increases by about $65 \mathrm{~h}$ or by $30 \%$. Since mean wind speeds hardly change, both more gale and more calm wind conditions tend to occur, particularly in winter. 

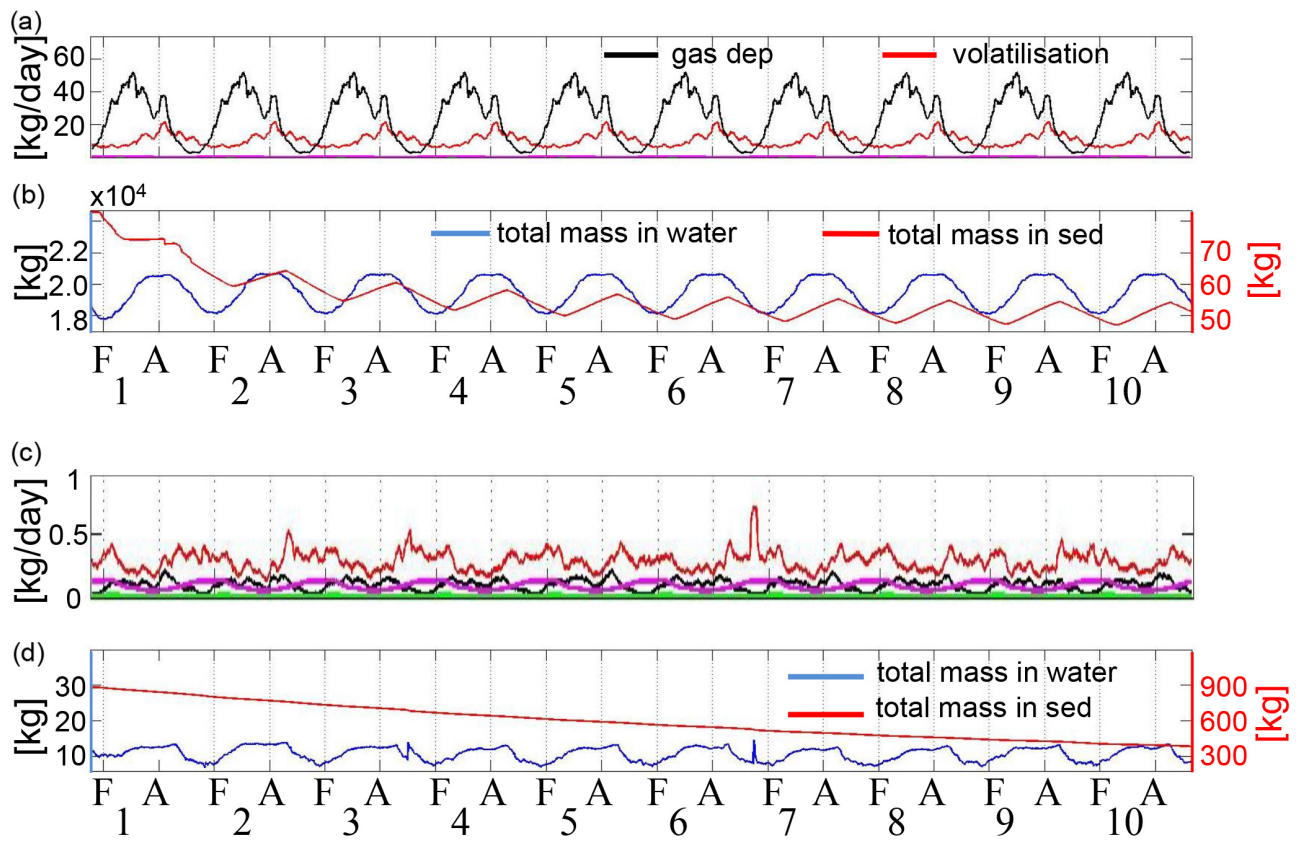

Figure 3. Time series of surface fluxes and total mass in water and sediment of $\gamma-\mathrm{HCH}$, top two panels, respectively, and the same for PCB 153, bottom two panels, respectively, for the period 2006-2015. February and August (F and A) and the year number (1-10) are shown on the $x$ axis. River input, wet deposition and dry deposition are plotted in magenta, green and blue (panels 1 and 3), respectively. Note the different scales (on the left and right) in second and bottom panels showing the different amounts of the substance in water and sediment.

The effect of the change in wind conditions during the 21 st century on bottom erosion and deposition of suspended particulate matter (SPM), which are important for our POP dynamics, is shown in Fig. 3c and d, respectively. Plots show trends of relative frequency of erosion and deposition periods in percentage points per 100 years, based on annual mean percentages of erosion and deposition for the 21st century. A slight increase/decrease in annual periods of erosion/deposition are found.

It is the effect of these changes on the studied POPs (previous paragraph) that are analysed. The full hydrodynamic analysis of the A1B scenario for the North Sea is to be discussed elsewhere.

\subsection{Time series of surface fluxes of $\gamma-\mathrm{HCH}$ and PCB 153 and total masses in water and sediment}

Time series of surface fluxes are given in Fig. 3 (2006-2015), Fig. 4 (2046-2055) and Fig. 5 (2090-2099). Air-sea exchange of $\gamma-\mathrm{HCH}$, top panels, is mostly due to dry gas deposition and volatilization, which are much greater than the other processes (wet deposition, particle deposition and river input). In general, dry gas deposition exhibits an annual cycle with greatest values in the spring and summer with peak values around May, and least values in autumn/winter, bottoming out in November-December when atmospheric concentrations are least (generally an order of magnitude or more less than in the summer months; Gusev et al., 2009). We remind the reader that partitioning of the POPs between air and water is dependent upon temperature, wind speed and the physical-chemical properties of the compound and its abundance in the environment. Thus, when dry gas deposition increases, concentration and total mass in water increases. This subsequently leads to increased volatilization, as described in the following paragraph.

Volatilization also exhibits a clear annual cycle, with greatest values in late summer and the early autumn months (August-September) and least values in late winter and early spring (February-March). Dry gas deposition is generally $2-4$ times greater than volatilization, except between about September and December, when deposition is lowest. Volatilization is still high at this time but decreases with the total mass in water curve, second panel, which in turn is due to the decrease in dry gas deposition.

Comparing the different time series, it is seen that in 2006 2015 there is very little inter-annual variability in dry gas deposition and volatilization of $\gamma-\mathrm{HCH}$ (Fig. 3) with dry gas deposition fluxes peaking at around $50 \mathrm{~kg} \mathrm{day}^{-1}$ in May, and volatilization at about $20 \mathrm{~kg} \mathrm{day}^{-1}$ in August-September. Contrast this with the 2046-2055 and 2090-2099 runs, respectively. Maximum gas deposition fluxes increases in most years in both runs, generally approaching $60 \mathrm{~kg} \mathrm{day}^{-1}$ in May and clearly exceeding it in four and three years in the 2050 and 2090 runs, respectively. Volatilization increases in the 2046-2055 run, relative to the 2006 run, and is even greater in the 2090 run. 

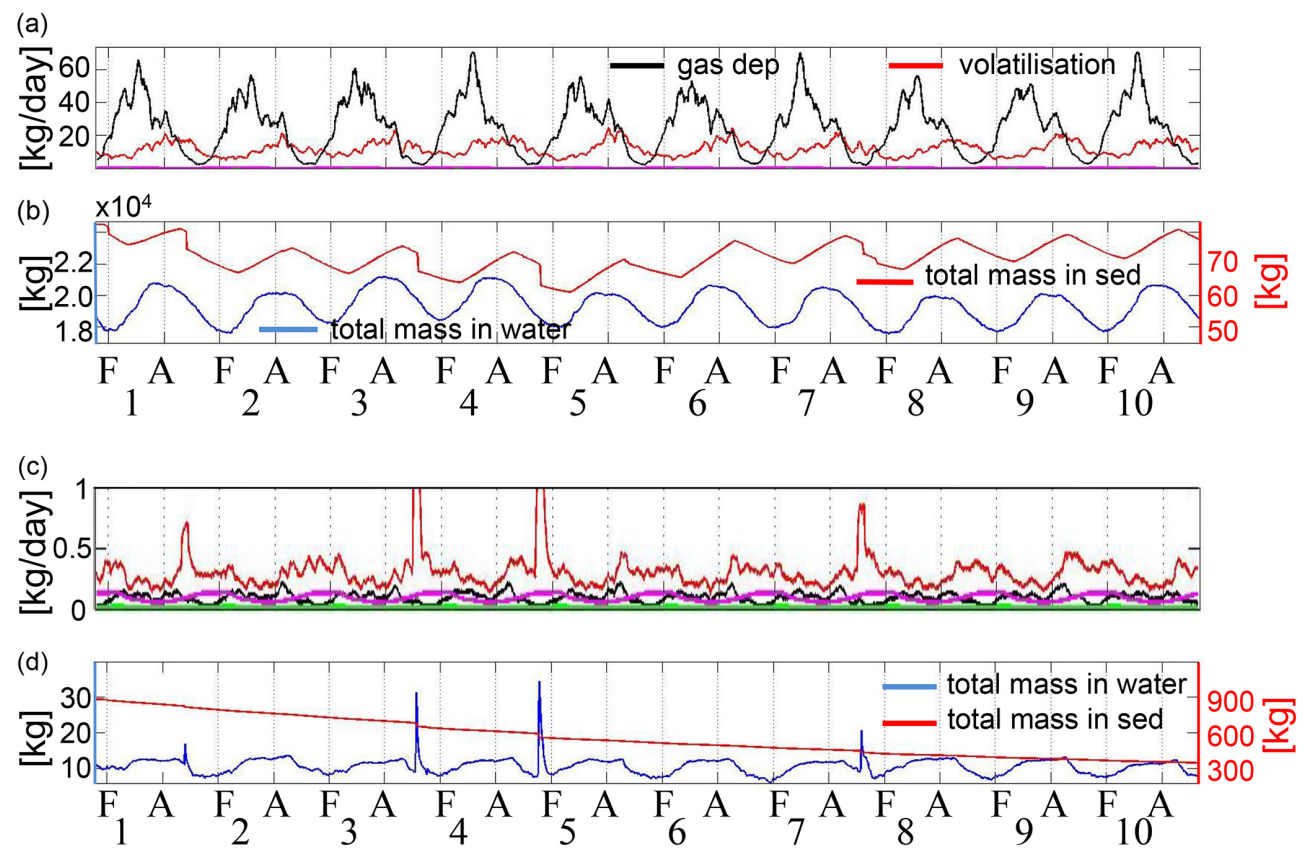

Figure 4. As Fig. 3, but for 2046-2055. Note the different scales (on the left and right) in second and bottom panels showing the different amounts of the substance in water and sediment.

So we conclude that climate change in the 21 st century results in increased dry gas deposition and volatilization of $\gamma-\mathrm{HCH}$. This is further discussed and clarified in Sect. 3.3.

Clear annual cycles in total mass of $\gamma-\mathrm{HCH}$ in water (Figs. 3-5, second panels) is seen in the three 10-year runs. Values are greatest around August and least around February, due to the accumulated net flux of dry gas deposition over volatilization in the spring and summer and the net deficit (reverse) in winter, respectively. Clear annual cycles in total mass of $\gamma-\mathrm{HCH}$ in sediment, second panels, are also seen for all three runs with maximum values observed around September-October and minimum values around MarchApril. The 1-2-month lag in these extrema, relative to the water column, is due to settling in summer and resuspension due to storm events and weather conditions in general in winter. Because of plankton blooms, more particulate organic carbon (POC) is contained in the water column in the spring and summer months. POPs sorb to this POC before ultimately sinking out of the water column and into sediment. In winter months, winds and stormy weather lead to resuspension of POPs (see discussion in O'Driscoll et al., 2013). Total mass is diminished somewhat in the first year of all three runs, which is consistent with the trend in 1996-2005 (O'Driscoll et al., 2013), where decreasing atmospheric concentrations and river input resulted in a downward trend of total mass in sediment. Note also that the total mass in water exceeds that in sediment by more than two orders of magnitude.

For PCB 153 (Figs. 3-5, third panels) volatilization (red) is greater than any of the surface sources, dry gas deposition (black) and river input (magenta) are generally 2-4 times less than volatilization, while particle (blue) and wet deposition (green) are much smaller. Volatilization and river input are in phase with largest values in winter and lowest in summer, while dry gas deposition is highest in spring and summer and least in winter. Volatilization generally exceeds the sum of the sources (deposition and river input), so that the North Sea is net volatilizational to the atmosphere for PCB 153, which was already shown to be the case for 1996-2005 (O'Driscoll et al., 2013), but can be net depositional in the summer months when the sum of dry gas, wet and aerosol deposition and river input can exceed volatilization. The other main feature is the peaks, or rapid increases, in volatilization due to storms.

A seasonal cycle in total mass of PCB 153 in water (Figs. 3-5, bottom panels) is seen with highest (lowest) values found in the summer (winter) months. Total mass is generally lowest in winter and starts to increase during the spring bloom (primary production) when depositional PCB 153 sorbs to POC in the water column. Values remain high through the spring and summer, when the North Sea can be net depositional for PCB 153, before decreasing in September-October, when the primary production decreases, reaching lowest values in January-February, thus completing the annual cycle. The spikes observed are the result of winter storms, which cause erosion of fine fraction of sediment and resuspension of the POP into the water column, resulting in rapid increases in total mass in water. The recovery time for these storms is about 1-2 months in the water column when concentrations return to pre-storm values. These events 

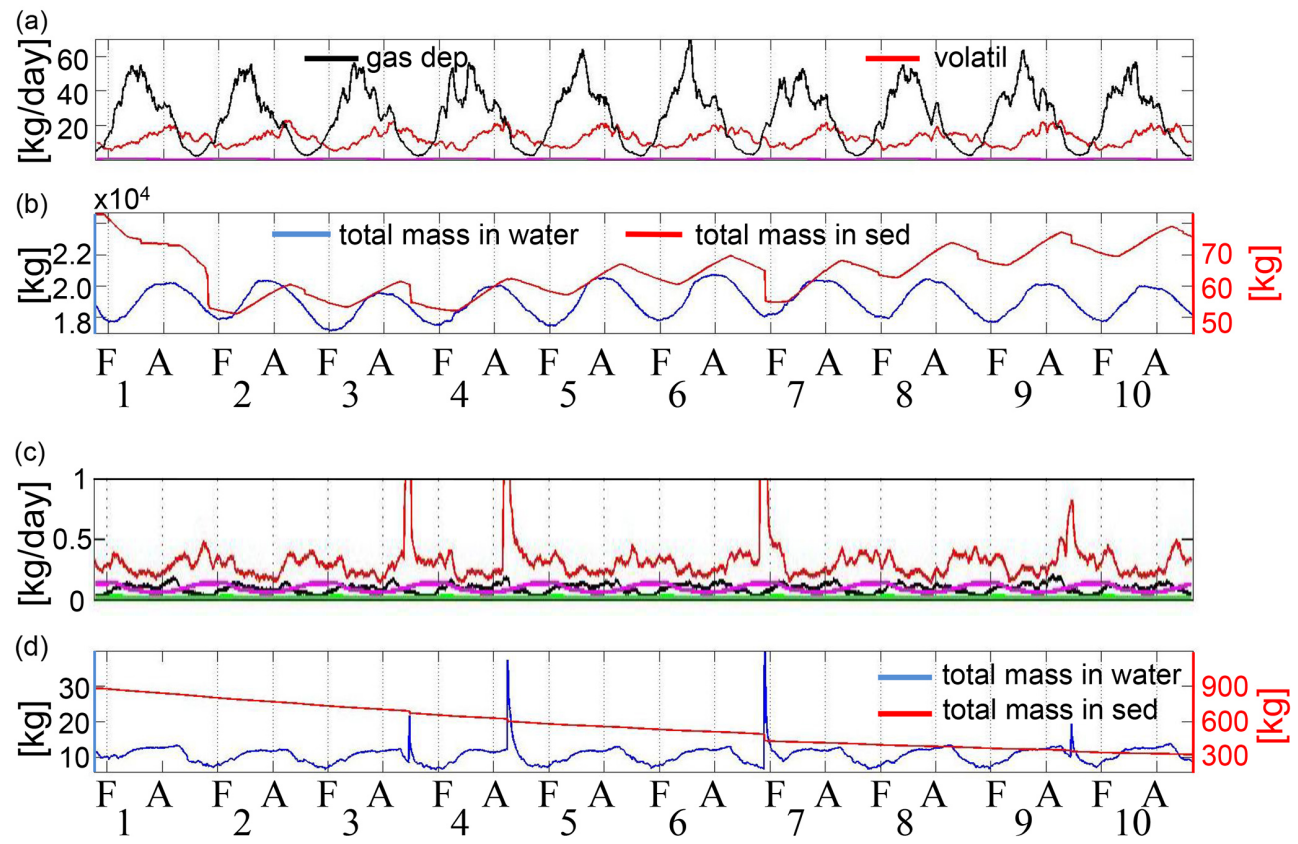

Figure 5. As Fig. 3. but for 2090-2099. Note the different scales (on the left and right) in second and bottom panels showing the different amounts of the substance in water and sediment.

are also found in the sediment and $\gamma-\mathrm{HCH}$ time series (total mass of PCB 153 in sediment decreases simultaneously, as does that of $\gamma-\mathrm{HCH}$ but so little of it is contained there, relative to water, that it makes no impression on the total mass in water time series).

Total mass of PCB 153 in sediment (Figs. 3-5, bottom panels) decays exponentially, with values reduced to less than half by the end of the three 10-year runs. An annual cycle, though not obvious, occurs with maximum values in spring and summer, due to primary productivity and sinking on POC, and minimum values in winter due to erosion resulting from storms and strong winds. Since PCB 153 is hydrophobic (or lipophilic) most of it sorbs to POC before settling in the sediment, and we see that total mass in sediment is more than an order of magnitude greater than that in water. Therefore, continuous resuspension of PCB 153 is enough to keep a constant small amount of it dissolved in water but the total mass in sediment will decay exponentially unless it is supplemented through atmospheric or river input.

During storm events, erosion causes mobilization and resuspension of PCB 153 into the water column, increasing its concentration there, thus resulting in a consequent increase in volatilization. Storms will generally resuspend sediment at depths of tens of metres, while very strong storms can cause resuspension down to $50 \mathrm{~m}$ or more. But most of the pollutants are found in shallow water, close to polluted rivers, in the southern North Sea (see O'Driscoll et al., 2013, Figs. 6 and 7). Because the total mass of PCB 153 in water is so much less than that in sediment, and because of increased volatilization during and following a storm, and net volatilization in general, the total mass in sediment cannot recover following a storm event. This is in contrast to $\gamma$ $\mathrm{HCH}$, which is generally net depositional from atmosphere to ocean, has total mass in water more than two orders of magnitude greater than that in sediment, and thus pre-storm mass in sediment can be recovered. From this, we conclude that the change in number and strength of storms, and with this erosion events, has only a small impact on the concentration of $\gamma-\mathrm{HCH}$ in sediment and water.

Concerning the predictability of North Sea storms, Weisse et al. (2005) found relatively good agreement between the NCEP-NCAR global reanalysis (Kalnay et al., 1996) and actual events, where storms events were generally reasonably reproduced for all parameters. Using a limited ensemble of 21 st century scenarios, Weisse et al. (2009) have been able to estimate potential future met-ocean conditions while also making a first guess about the underlying uncertainties. The increased number of storms they found (Weisse et al., 2009, Fig. 4), makes us even more confident about the increase in storm size and number found in our scenario runs, particularly in the 2090-2099 decade.

\subsection{Comparison of time series of total mass of $\gamma-\mathrm{HCH}$ and PCB 153 in water and sediment}

Time series of total mass of $\gamma-\mathrm{HCH}$ and PCB 153 in water and sediment for the entire model domain for the three 10 -year runs are plotted against each other for comparison in Fig. 6. For $\gamma$-HCH in water (Fig. 6a) there is little inter-annual variability, the annual cycle generally faithfully 

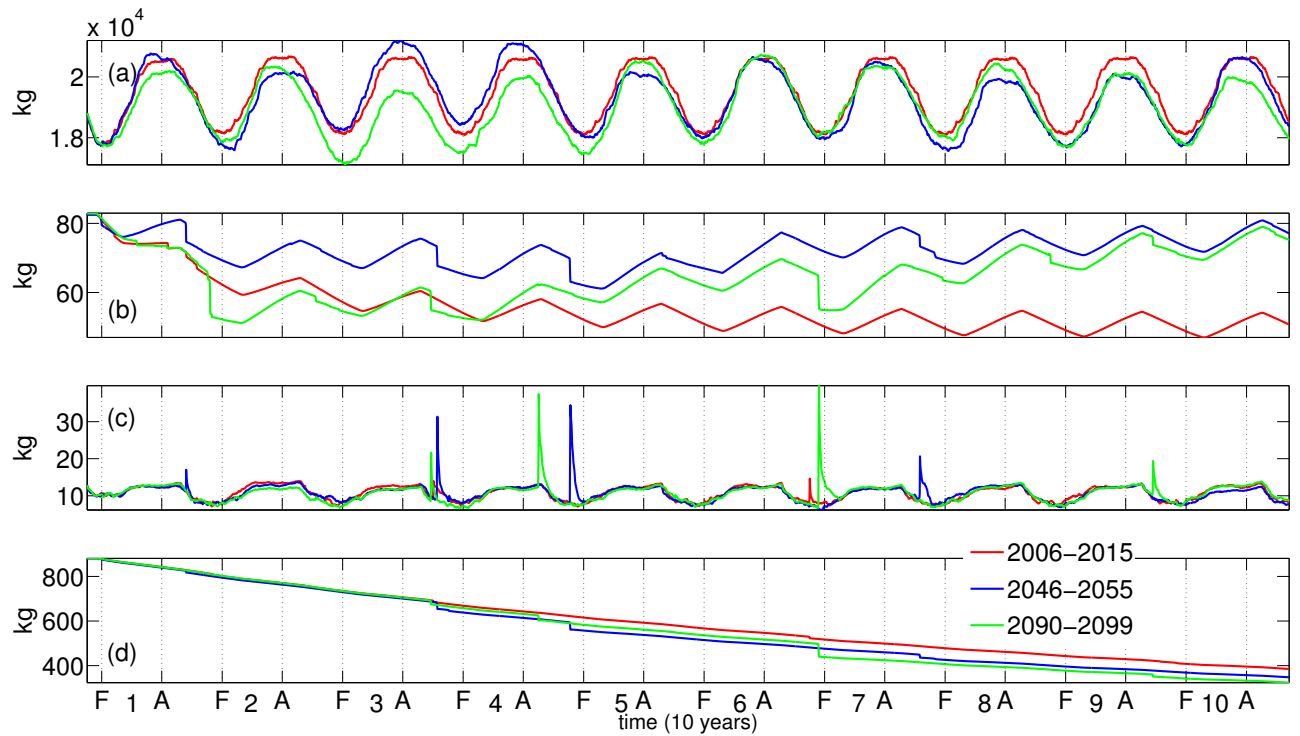

Figure 6. Time series of total mass of $\gamma-\mathrm{HCH}$ in water (a), and sediment (b), and PCB 153 in water (c), and sediment (d), for the three 10-year periods 2006-2015, 2046-2055 and 2090-2099. February and August (F and A) and the year number (1-10) are shown on the $x$ axis. The time series presented in this paper are the sum values within the model domain.

repeating itself. The almost identical repetition of the annual cycle of dry gas deposition and volatilization in 2006-2015 (Fig. 3, top panel) results in the repeated corresponding annual cycle for total mass in water. Inter-annual variability in both dry gas deposition and volatilization for both future runs (Figs. 4 and 5, top panels) are responsible for the same variability in total mass in water. For example, the increase in dry gas deposition in the third and fourth years of the 2046 run, relative to the 2006 run, results in the increase in mass in water, while decreasing deposition and increasing volatilization are responsible for the decrease in mass in water in the eighth and ninth years. In the 2090 run the increase in volatilization, relative to that in dry gas deposition (Fig. 5) in the second to fifth and the last three years is responsible for the decrease in total mass in water.

Comparing total mass of $\gamma-\mathrm{HCH}$ in sediment for the three runs (Fig. 6b) shows that while the mass diminishes somewhat in the first year of all three runs (by $\sim 20 \%$ in 2006, $15 \%$ in 2046 and $40 \%$ in 2090), it continues to decrease between 2006-2011 (to 60\% of 2006 mass in 2011) but remains steady thereafter; it diminishes a little further in the period 2047-2049 (to 80\% of 2046 values) but increases thereafter to 2055 (back to initial values); and following a decrease resulting from a storm in 2091 it increases from 20922099, also back to initial levels. So there is an upward trend of mass in sediment in the future runs relative to the present (2006-2015). This is due to increased dry gas deposition in the future runs, which causes an increase of the amount of $\gamma$ $\mathrm{HCH}$ sorbing to POC in the water column and, subsequently, resulting in sinking of an increased mass of the POP into the sediment. This small increase of total mass in sediment is not observed in the water column in Fig. 6a because it is small relative to total mass in the water column.

Comparing total masses of PCB 153 in water (Fig. 6c), it is seen the mass remains steady for all three cases. In sediment (Fig. 6d), total mass in the 2090-2099 run decreases faster than the 2046-2055 run, which decreases faster again than the 2006-2015 run. This is due to the increased number and intensity of storms observed in the 2050 and 2090 runs. These storms cause resuspension of PCB 153 into the water column, part of which becomes available for volatilization due to the equilibrium partitioning of the POP.

\subsection{Annual fluxes of $\gamma$-HCH and PCB 153}

Total annual mass fluxes of $\gamma-\mathrm{HCH}$ and PCB 153 for 2015, and the ratio of the fluxes for the years 2055/2015 and 2099/2015 are presented in Fig. 7. The patterns are fairly similar for each of the two POPs but there are important differences. The sum of the sources is always less than the sum of the sinks, with some variability in the different years and chemicals.

For $\gamma-\mathrm{HCH}$, dry gas deposition and volatilization both increase somewhat in the future runs $(2055,2099)$, relative to the present (2015). Gas deposition is up by $7.5 \%$ and $4.0 \%$, while volatilization is up $15.9 \%$ and $16.1 \%$ in 2055 and 2099 , respectively, relative to 2015 . These changes are due to increased air and water temperature and wind speed, see supplementary information for details. Degradation flux (the total mass that is degraded) in water decreases, down by $1 \%$ and $3 \%$ in 2055 and 2099, respectively, but remains higher than dry gas deposition. Exchange at the open boundaries is fairly negligible. Total sum of sources increase by $7.3 \%$ and 

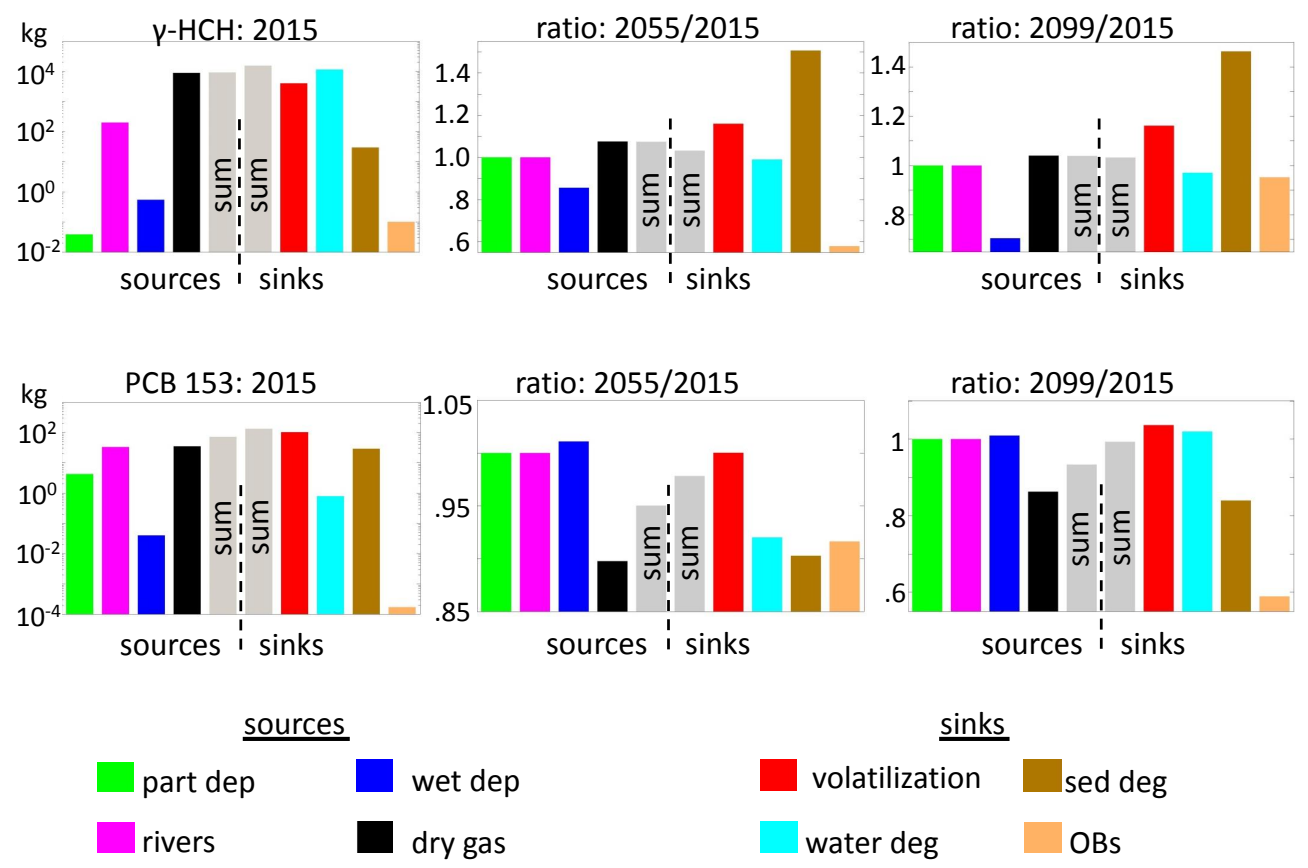

Figure 7. Total annual mass fluxes, [kg] $\log 10$ scale, of North Sea sources and sinks for 2015, left panels. Ratios of total annual mass fluxes: 2015/2055 (centre panels) and 2099/2015 (right panels). Sources are deposition with particles, input through rivers, wet deposition and gas deposition. Sinks are volatilization, degradation in water, degradation in sediment and net outward flux through the open ocean boundaries (OBs). The sums of sources and sinks are given by the grey panels.

$3.9 \%$, and sinks by $3.2 \%$ and $2.6 \%$ in 2055 and 2099 , respectively.

For PCB 153, dry gas deposition decreases in the future runs, by $10.3 \%$ and $13.7 \%$ in 2055 and 2099, respectively, while volatilization increases, by less than $1 \%$ in 2055 and $3 \%$ in 2099. This is in agreement with Lamon et al. (2009) who found that higher temperatures increased primary and secondary volatilization emissions of PCBs, thereby enhancing transport from temperate regions to the Arctic. Degradation flux in sediment decreases due to decreased mass there, to $90 \%$ and $84 \%$ of 2015 values in 2055 and 2099, respectively. Exchange at the open boundaries is fairly negligible. Sum of sources decreases by 5 and $7 \%$ in 2055 and 2099, respectively, while the sinks decrease by 2 and $1 \%$, respectively.

Wöhrnschimmel et al. (2013) also found that modelled concentrations of PCB153 and $\alpha-\mathrm{HCH}$ in Arctic contamination increase in air and water by a factor of 2 , given a phase of ongoing primary emissions, increases of up to a factor of 2 in air and 4 in water following a phase-out, mostly driven by emissions, and attributed to transport and fate changes of the substances. This also agrees with our results and those of Lamon et al. (2009), whereby higher concentrations would be partially due to transport of the chemicals into the Arctic from lower latitudes.

So the general result is that there are small changes in annual mass fluxes due to the changing climate.

\subsection{Spatial changes of concentrations in water and sediment}

Distributions of vertically integrated concentration ratios for the summer season (JJA) and the winter season (DJF) of $\gamma$ $\mathrm{HCH}$ and PCB 153 between 2005 and the last year of the three model runs are plotted in Fig. 8 (2015/2005, 2055/2005 and 2099/2005). Clear seasonal trends and patterns are apparent in both cases. PCB 153 values are mostly less than 1 (decreased relative to 2005) while $\gamma-\mathrm{HCH}$ ratios are often greater than 1 (increased relative to 2005).

Starting with $\gamma-\mathrm{HCH}$, the first feature that stands out is the region of decreased concentration in the future runs (blue) in the very south of the model domain. The reasons for this are twofold. First, concentration in gas in the atmosphere is greatest along the British coast, particularly around southern England and the Thames estuary. Concentrations in 2005 are substantially reduced relative to earlier years (e.g. about $2-4$ fold less than in 2000 and around 20-30\% less than in 2004, see Gusev et al., 2009). Dry gas depositions are also greatest adjacent to the British coast and have also been shown to drop substantially between 1997 and 2004 (see Fig. 11 in O'Driscoll et al., 2013). Secondly, the Thames and Rhine are two major river point sources. Although the total flux of river sources into the North Sea is more than an order of magnitude less than dry gas deposition, they are substantial local sources. These concentrations have also dropped substantially annually since 1995 (see O'Driscoll et al., 2013, 

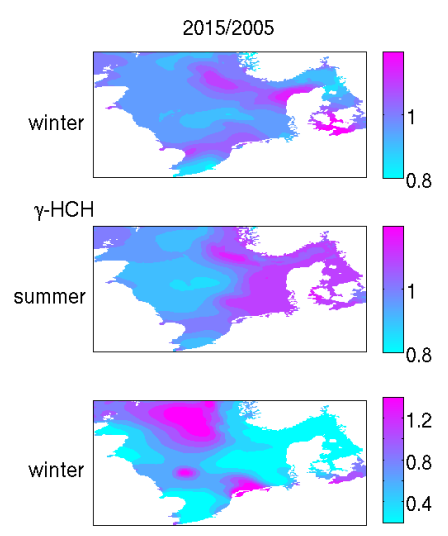

PCB 153

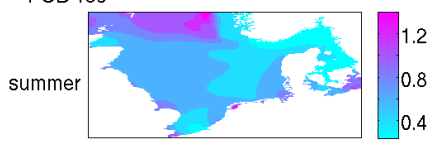

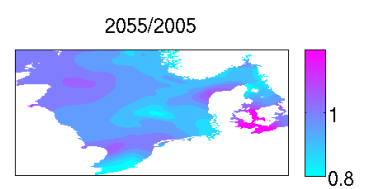
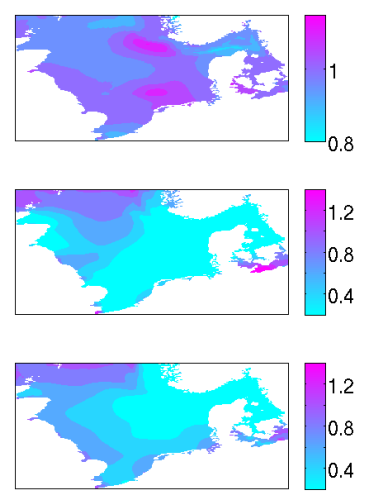
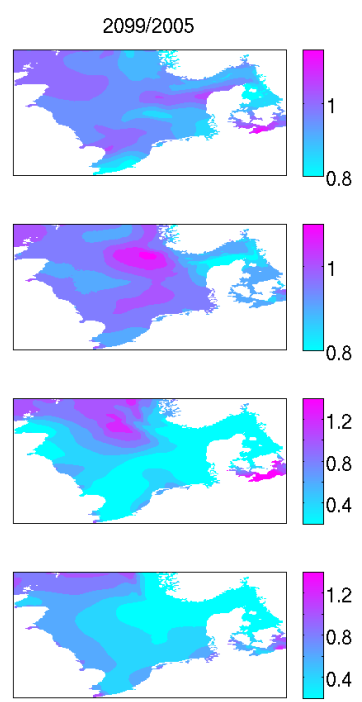

Figure 8. Distributions of concentration ratios integrated through the entire water column, 2015/2005, 2055/2005 and 2099/2005, from left to right, respectively, for $\gamma-\mathrm{HCH}$ in winter (top) and summer (second row), and for PCB 153 in winter (third row) and summer (bottom). Units are $\mathrm{ng} \mathrm{L}^{-1}$.

for details). Together, these changes combine and result in the reduced concentration band found in the very south of the model domain. Outside of this region, a number of regions of increased and decreased change are seen. The two regions of increased concentration in the future (pink) between East Anglia and the IJsselmeer and to the west of Jutland and the Norwegian coast (winter) diminish in the future runs because of increased water temperature, leading to increased volatilization. In summer, increases (pink) are greatest away from the British coast where gas concentrations have not been substantially reduced. This is modulated by the inflow of lower concentration Atlantic water.

For PCB 153, winter distributions are fairly similar for the three years, although somewhat higher values are found out to the open North Atlantic and in the IJsselmeer region, which can be put down to stronger inflow at the open boundary and stronger bottom currents in the southern North Sea, respectively. Lesser future decreases in concentration are also found near British and Dutch rivers, between southern Britain and Holland, around German river sources, out into the German Bight and Wadden Sea, and into the Kattegat. This is due to the decreased resuspendable content of PCB 153 in the sediment, compared to 2005 , as a result of previously ongoing higher erosion activities, in combination with the anti-clockwise circulation that carries these polluted waters into the Kattegat. In summer, concentrations are somewhat reduced in 2055 and 2099 relative to 2015, which is due to the decrease in dry gas deposition in the future runs (2055 and 2099) and reduced concentrations in sediment. In summer, ratios are generally less than 1 , with values of 1 or slightly greater found at the open North Atlantic boundaries.
Distributions of ratios in summer and winter in sediment between the last year of each of the three model runs and 2005 are shown in Fig. 9 (2015/2005, 2055/2005 and $2099 / 2005$ ). For $\gamma-\mathrm{HCH}$, concentrations are generally reduced from 2005 values. The greatest losses (blue) are found in 2015 when dry gas deposition is less than in 2055 and 2099 , with high values found particularly around the southern British and continental coasts and southernmost regions of the North Sea. Patterns are similar in winter and summer but values are lower in summer (less blue) due to increased dry gas deposition, particularly in 2055 and 2099. Increased concentrations are seen off the western and northern parts of Jutland in all three runs but are greater in 2055 and 2099, and, also, in the future runs, off parts of the British and continental coasts and small areas of the southern North Sea, which can be due to the increased dry gas deposition but also erosion and redeposition in coastal areas, in particular close to river sources (see O'Driscoll et al., 2013, for distributions in 2004).

For PCB 153, there is little notable change in distributions and concentrations between 2005 and the last year of each of the three runs. This is due to the large masses in sediment that have been either degraded or eroded (Figs. 3-7) and account for most of the difference. However, it is interesting to plot the ratios at the end of the three 10-year runs against themselves (Fig. 10). Beginning with the winter plots, higher values in 2015 relative to 2055 (dark pink) are found in the coastal regions of the southern North Sea, especially around the Wash, Thames, offshore of the Rhine and southern Dutch coast, and offshore of the Elbe and the Wadden Sea region, which is due to increased gale conditions in the 2055 run. Areas of decrease are also found in the southern 

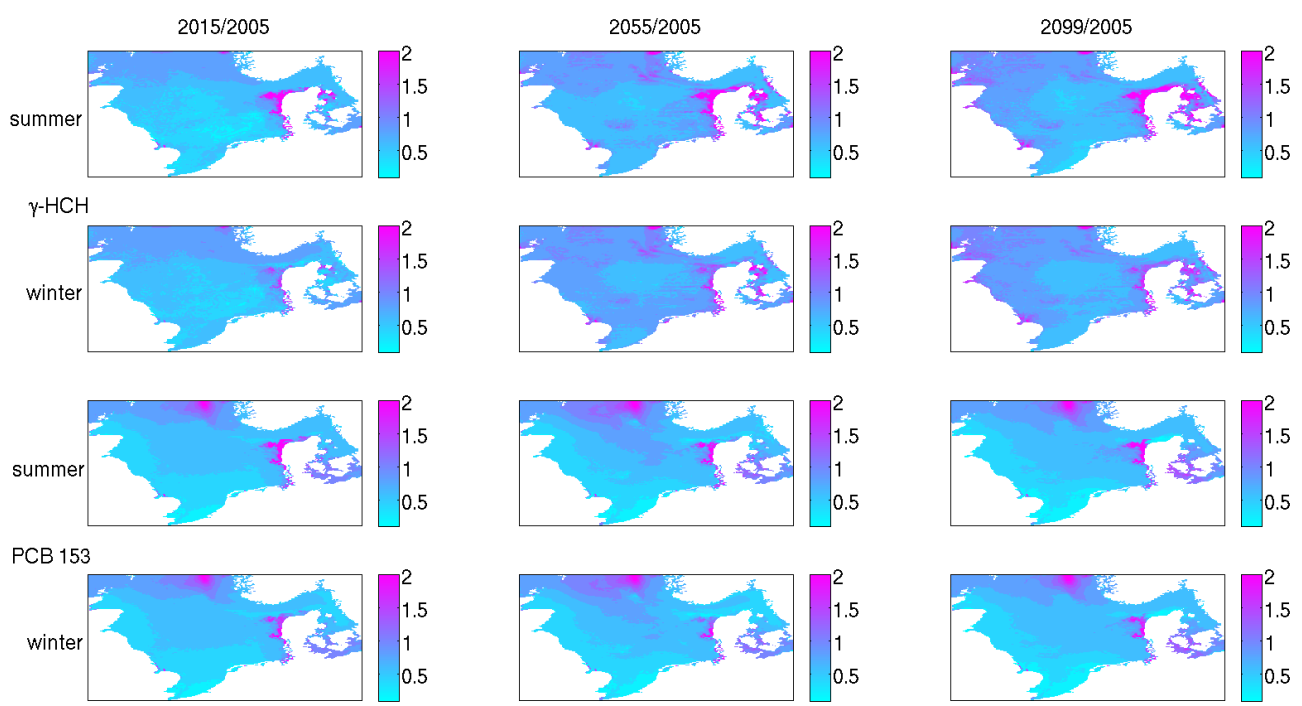

Figure 9. Distributions of concentration ratios in sediment, 2015/2005, 2055/2005 and 2099/2005, from left to right, respectively, for $\gamma$-HCH in winter (top) and summer (second row), and PCB 153 in winter (third row) and summer (bottom). Units are ng $\mathrm{g}^{-1} \mathrm{dry}$ weight.

and northern North Sea but their magnitude is small, though there is a region of higher increase around the Firth of Forth and Moray Firth which may be due to localized storms in the 2015 run. Increases in 2015 relative to 2099 are again found in the aforementioned areas of the southern North Sea but this time extend along the entire British coast and an extended area seaward of the Wash. This is to be expected due to the increased stormy conditions. For the 2055/2099 case, large positive values are seen from East Anglia up to the northern Scottish coast, indicating stronger storm activity here in the 2090s, which is to be expected from examining the previous two plots. Large negative values are found around the Thames, central Dutch coast, Friesian Islands, German Bight, and Wadden Sea, and are also as expected from the previous two plots. Summer patterns are similar to those in winter, since most of the erosion takes place in winter, but some differences are found which can be the result of both deposition and erosion.

\section{Summary and conclusions}

The impact of climate variability on the fate and cycling of two selected legacy POPs, $\gamma-\mathrm{HCH}$ and PCB 153, in the North Sea in the 21st century, is investigated with a combined hydrodynamic (HAMSOM) and Fate and Transport Ocean Model (FANTOM). Future scenario model runs for three 10-year periods to the year 2100 (2006-2015, 20462055 and 2090-2099) using plausible levels of both in situ concentrations and atmospheric, river and open boundary inputs are performed. Our approach was to reutilize 2005 POP values in the atmosphere, rivers and at the open boundaries for every year of the simulations, while using the (final) result of our 1996-2005 runs, see O'Driscoll et al. (2013), as the initial condition for all three future runs. In this way, differences between the three 10-year simulations are attributed to climate change only.

Dry gas deposition and volatilization of $\gamma-\mathrm{HCH}$ increase in the future, relative to the present, and volatilization in 2090-2099 is even greater than 2046-2055, as the direct result of hydrodynamic forcing due to climate change.

Total mass of PCB 153 in sediment decreases exponentially in all three runs due to degradation in sediment, but also due to erosion and subsequent volatilization, particularly during storms, and concentrations in rivers and the atmosphere are not high enough to sustain sediment concentration levels. Total mass decreases even faster in the future runs, relative to the present, because of the increased number and intensity of storms. $\gamma-\mathrm{HCH}$ is also eroded during storms, but concentrations in sediment are recovered because so much of it is dissolved in water. Increased dry gas deposition of $\gamma-\mathrm{HCH}$ in the future results in more of it sorbing to POC in the water column, thus the increase of it in sediment in the future runs.

Annual net sinks exceed annual net sources at the end of all periods, leading to a loss of POPs in the system. Annual fluxes into and out of the North Sea system for both POPs show a slight future decrease during the simulations and also the second and third periods relative to the first period. The North Sea is net volatilizational for PCB 153, while $\gamma$-HCH is net depositional at the North Sea surface.

For the last year of each of the three runs, concentrations of $\gamma-\mathrm{HCH}$ in the water column are decreased relative to 2005 between the Thames and Rhine estuary regions due to decreased river and atmospheric concentrations. For PCB 153 there are no notable differences between the three runs in winter, but concentrations are somewhat reduced in summer in the future runs because of reduced dry gas deposition 

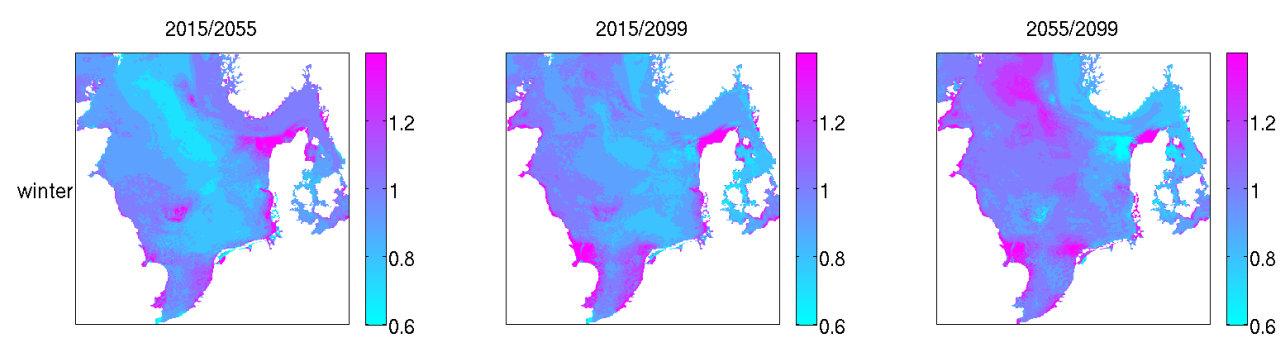

PCB 153
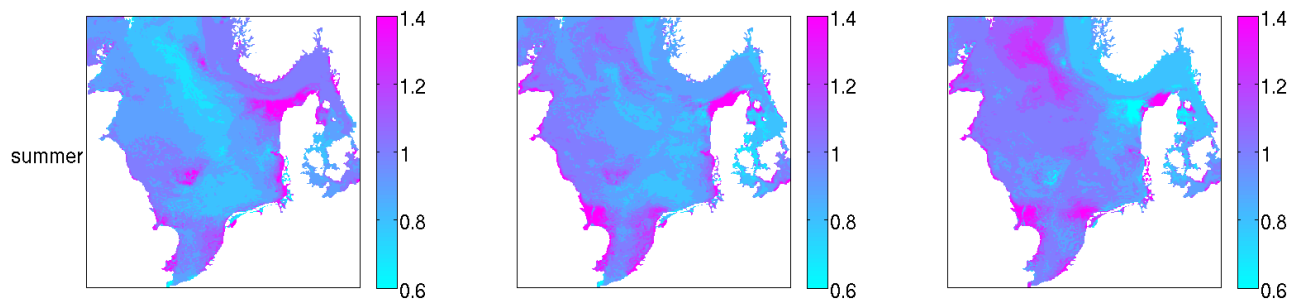

Figure 10. Distributions of concentration ratios of PCB 153 in sediment at the end of the three runs, 2015/2055, 2015/2099 and 2055/2099, from left to right, respectively, in winter (top) and summer (bottom). Units are $\mathrm{ng} \mathrm{g}^{-1}$ dry weight.

and reduced concentrations in sediment. In winter, future decreases are found near British and Dutch rivers and the southern North Sea generally.

In sediment, concentrations of $\gamma-\mathrm{HCH}$ are generally reduced in the future runs relative to 2005 , with greatest losses found in 2015 because of less dry gas deposition relative to 2055 and 2099. For PCB 153, there is little notable change in distributions and concentrations between 2005 and the last of each of the three 10-year runs, which is due to the large amount of sediment that has been either degraded or eroded.

The results agree with other studies that found increased volatilization of PCBs due to rising temperatures, thus contributing to increased transport from temperate regions to the Arctic (Lamon et al., 2009; Gouin et al., 2013; Armitage et al., 2011; Wöhrnschimmel et al., 2013). There is some uncertainty though, since investigators using global multimedia models found that concentrations of PCB153 and $\alpha-\mathrm{HCH}$ in Arctic contamination increase in air and water by factors of 2 to 4 (Wöhrnschimmel et al., 2013), respectively, whereas volatilization rates of PCB 153 in our model increase by only a few percent. We remind the reader there are differences between our modelling approach and assumptions and those of Wöhrnschimmel et al. (2013). Wöhrnschimmel et al. (2013) present 150 -year simulations driven by global-scale emission estimates over time. Accordingly, the modelled responses to climate change are not directly comparable in terms of absolute magnitude. Wöhrnschimmel et al. (2013) found that the key influences on surface ocean concentrations in the Arctic for PCB 153 are temperature-driven increases in primary emissions and reductions in sea ice cover. Although the increased volatilization of North Sea POPs would lead to increased concentrations in the Arctic, it appears that other sources would also have to contribute to the increase, even though the increased rates in marginal seas would contribute substantially to increased concentrations found in the Arctic.

Finally, although the influence of climate change on the two POPs simulated here is generally small, the increased number and magnitude of storms in the 21 st century will result in large amounts of hydrophobic POPs being resuspended in shallow seas with ensuing revolatilization events. This can have important consequences including movement of POPs up through the marine food chain and delivery of POPs into Europe.

\section{The Supplement related to this article is available online at doi:10.5194/os-10-397-2014-supplement.}

Acknowledgements. The authors thank the German Science Foundation(DFG) for funding the project under grant no. PO 614/8-1. The authors thank Tatiana Ilyina and Thomas Pohlmann for valuable discussions. We thank four reviewers for their thoughtful comments.

Edited by: M. Hoppema

\section{References}

AMAP Assessment Report: Arctic Pollution Issues: Arctic Monitoring and Assessment Programme, Oslo, Norway, 1998.

Armitage, J. M., Quinn, C. L., and Wania, F.: Global climate change and contaminants - an overview of opportunities and priorities for modelling the potential implications for long-term human exposure to organic compounds in the Arctic, J. Environ. Monitor., 13, 1532-1546, 2011. 
Backhaus, J. O.: A three-dimensional model for the simulation of shelf sea dynamics, Deutsche Hydrographische Zeitschrift, 38, 165-187, 1985.

Breivik, K., Sweetman, A., Pacyna, J. M., and Jones, K. C.: Towards a global historical emission inventory for selected PCB congeners - A mass balance approach: 3. An update, Sci. Total Environ., 377, 296-307, 2007.

Ghosh, S., Zang, S., Mitra, P. S., Ghimbovschib, S., Hoffman, E. P., and Dutta, S. K.: Global gene expression and Ingenuity biological functions analysis on PCBs 153 and 138 induced human PBMC in vitro reveals differential mode(s) of action in developing toxicities, Environ. Int., 37, 838-857, doi:10.1016/j.envint.2011.02.010, 2011.

Gioia, R., Nizzetto, L., Lohmann, R., and Dachs, J.: Polychlorinated biphenyls (PCBs) in air and seawater of the Atlantic Ocean: sources, trends and processes, Environ. Sci. Technol., 42, 14161422, 2008.

Gouin, T., Armitage, J., Cousins, I., Muir, D., Ng, C. A., Reid, L., and Tao, S.: Influence of global climate change on chemical fate and bioaccumulation: The role of multimedia models, Environ. Toxicol. Chem., 32, 20-31, 2013.

Gusev, A., Rozovskaya, O., Shatalov, V., Sokovyh, V., Aas, W., and Breivik, K.: Persistent Organic Pollutants in the Environment, EMEP Meteorological Synthesizing Centre-East, Status Report, 3, 77 pp., 2009.

Hornsby, A. G., Wauchope, R. D., and Herner, A. E.: Pesticide Properties in the Environment, Springer-Verlag, New York, 1996.

Ilyina, T., Pohlmann, T., Lammel, G., and Sündermann, J.: A fate and transport ocean model for persistent organic pollutants and its application to the North Sea, J. Marine Syst., 63, 1-19, 2006.

Jacob, D., Van den Hurk, B. J. J. M., Andrae, U., Elgered, G., Fortelius, C., Graham, L. P., Jackson, S. D., Karstens, U., Käopken, C., Lindau, R., Podzun, R., Rockel, B., Rubel, F., Sass, B. H., Smith, R. N. B., and Yang, X.: A comprehensive model inter-comparison study investigating the water budget during the BALTEX-PIDCAP period, Meteorol. Atmos. Phys., 77, 19-43, 2001.

Jungclaus, J. H., Botzet, M., Haak, H., Keenlyside, N., Luo, J. J., Latif, M., Marotzke, J., Mikolajewicz, U., and Roeckner, E.: Ocean circulation and tropical variability in the coupled model ECHAM5/MPI-OM, J. Climate, 19, 3952-3972, doi:10.1175/JCLI3827.1, 2006.

Kalnay, E., Kanamitsu, M., Kistler, R., Collins, W., Deaven, D., Gandin, L., Iredell, M., Saha, S., White, G., Woollen, J., Zhu, Y., Chelliah, M., Ebisuzaki, W., Higgins, W., Janowiak, J., Mo, K. C., Ropelewski, C., Wang, J., Leetmaa, A., Reynolds, R., Jenne, R., and Joseph, D.: The NCEP/NCAR 40-year reanalysis project, B. Am. Meteorol. Soc., 77, 437-471, 1996.

Lamon, L., von Waldow, H., MacLeod, M., Scheringer, M., Marcomini, A., and Hungerbuhler, K.: Modeling the global levels and distribution of Polychlorinated Biphenyls in air under a climate change scenario, Environ. Sci. Technol., 43, 5818-5824, 2009.
Larsen, J. and She, J.: Optimisation of a bathymetry database for the North European Shelf Seas, Technical Report 01-21, Danish Meteorological Institute, 2001.

Lohmann, R., Breivik, K., Dachs, J., and Muir, D.: Global fate of POPs: Current and future research directions, Environ. Pollut., 150, 150-165, 2007.

Mayer, B., Damm, P. E., Pohlmann, T., and Rizal, S.: What is driving the ITF? An illumination of the Indonesian throughflow with a numerical nested model system, Dynam. Atmos. Oceans, 50, 301-312, doi:10.1016/j.dynatmoce.2010.03.002, 2010.

Ngabe, B., Bidleman, T. F., and Falconer, R. L.: Base Hydrolysis of alpha- and gamma- Hexachlorocyclohexanes, Environ. Sci. Technol., 27, 1930-1933, 1993.

Nizzetto, L., Lohmann, R., Gioia, R., Dachs, J., and Jones, K. C.: Atlantic ocean surface waters buffer declining atmospheric concentrations of persistent organic pollutants, Environ. Sci. Technol., 44, 6978-6984, doi:10.1021/es101293v, 2010.

O’Driscoll, K., Mayer, B., Ilyina, T., and Pohlmann, T.: Modelling the cycling of persistent organic pollutants (POPs) in the North Sea system: fluxes, loading, seasonality, trends, J. Marine Syst., 111-112, 69-82, doi:10.1016/j.jmarsys.2012.09.011, 2013.

Orlanski, I.: A simple boundary condition for unbounded hyperbolic flows, J. Comput. Phys., 21, 251-269, 1976.

Pohlmann, T.: A meso-scale model of the central and southern North Sea: Consequences of an improved resolution, Cont. Shelf Res., 26, 2367-2385, 2006.

Roeckner, E., Brokopf, R., Esch, M., Giorgetta, M., Hagemann, S., Kornblueh, L., Manzini, E., Schlese, U., and Schulzweida, U.: Sensitivity of simulated climate to horizontal and vertical resolution in the ECHAM5 atmosphere model, J. Climate, 19, 37713791, 2006.

Sinkkonen, S. and Paasivirta, J.: Degradation half-life times of PCDDs, PCDFs and PCBs for environmental fate modeling, Chemosphere, 40, 943-949, 2000.

$\mathrm{Su}$, J. and Pohlmann, T.: Wind-topography interaction in an upwelling system in the eastern Hainan coast, J. Geophys. Res., 114, C06017, doi:10.1029/2008JC005018, 2009.

Weisse, R., von Storch, H., and Feser, F.: Northeast Atlantic and North Sea storminess as simulated by a regional climate model 1958-2001 and comparison with observations, J. Climate, 18, 465-479, 2005.

Weisse, R., von Storch, H., Callies, U., Chrastansky, A., Feser, F., Grabbemann, I., Günther, H., Pluess, A., Stoye, T., Tellkamp, J., Winterfeldt, J., and Woth, K.: Regional meteorological-marine reanalyses and climate change projections: Results for Northern Europe and potential for coastal and offshore applications, B. Am. Meteorol. Soc., 90, 849-860, 2009.

Wöhrnschimmel, H., MacLeod, M., and Hungerbühler, K.: Emissions, fate and transport of persistent organic pollutants to the Arctic in a changing global climate, Environ. Sci. Technol., 47, 2323-2330, 2013. 